\title{
Schwannoma Palate in Children: Rare Case
}

\author{
Barhmi I*, Tazi N, Mahdoufi R, Abada R, Rouadi S, Roubal M and Mahtar M \\ ENT Department, 20 august1953 Hospital, Chu Ibn Rochd, Casablanca, Morocco
}

${ }^{*}$ Corresponding author: Barhmi I, ENT Department and Chirurgiecervico - Facial, 20 August 1953 Hospital, 6 Rue Lahssen Elaarjoun, Casablanca, Morocco, E-mail: ismailbarhmi@gmail.com

Citation: Barhmi I, Tazi N, Mahdoufi R, Abada R, Rouadi S, et al. (2016) Schwannoma Palate in Children: Rare Case. J Case Rep Stud 4(2): 202. doi: 10.15744/2348-9820.4.202

Received Date: December 02, 2015 Accepted Date: April 15, 2016 Published Date: April 18, 2016

\begin{abstract}
Schwannoma is a benign tumor that originates from the presence of Schwann cells of the peripheral nerves. They are usually asymptomatic, do not recur, and malignant transformation is rare.

Schwannomas are frequently located in the soft tissues of head and neck region, but only a $1 \%$ of them are located in the oral cavity.

Here we describe a clinical case of Schwannoma located in the palate, which was histopathologically diagnosed as schwannoma. The lesion was completely excised intraorally. We also review the main clinical and histological characteristics of this pathology.

Keywords: Schwanoma; Palate; Neurolemmoma
\end{abstract}

\section{Introduction}

Schwannomas are slow-growing benign tumors that are derived from the schwann cells. It is also named neurilemoma, neurinoma and Schwann cell tum [1]. When intraoral, the tongue is the most favored site [2]. The involvement of the palate is a rare presentation.

Schwannomas can occur at any age but most commonly in the third and fourth decade of life, with no gender predilection [3]. The present case aims to highlight the diagnosis, investigation and management of schwannoma occurring in an unusual palatal location.

\section{Clinical Case}

We present a clinical case of schwannoma in a 13-year-old patient who attended the clinic for a persistent swelling on the right side of the palate, present for Six months. The mass was firm and relatively mobile. The mucosa over the tumor was normal. There were no complaints of pain, irritation, sudden increase in size or any other mass/swelling in the neck or other parts of the body. There was no medical history of interest.

On intra-oral examination, a single swelling on the right palatal region about $2 \mathrm{~cm}$ in size, with diffuse borders was noticed .The swelling was firm in consistency and non-tender (Figure 1). Routine hemogram and other biochemical parameters were within normal limits.

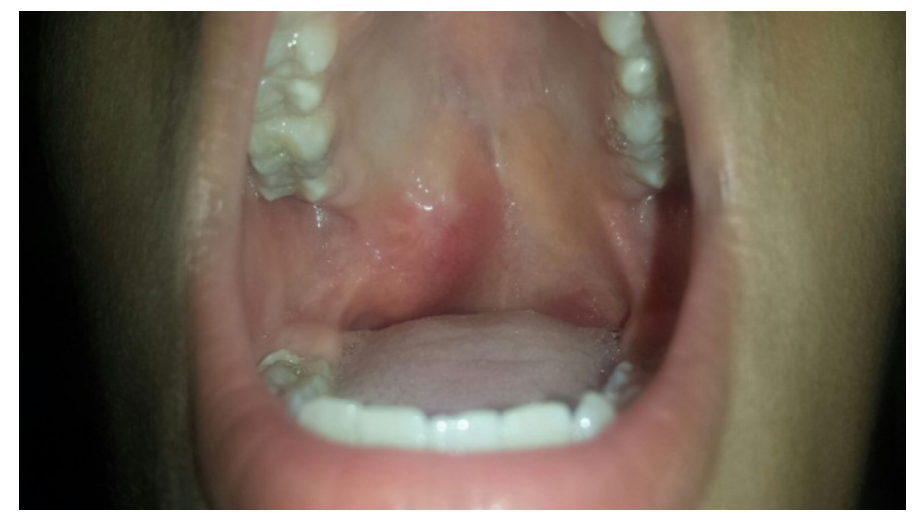

Figure 1: A single swelling on the right palatal region 
Computed tomography was requested which revealed a homogeneous mass, slightly less dense than the muscle, with well-defined borders, and without infiltrating the surrounding tissues, which were normal (Figure 2).

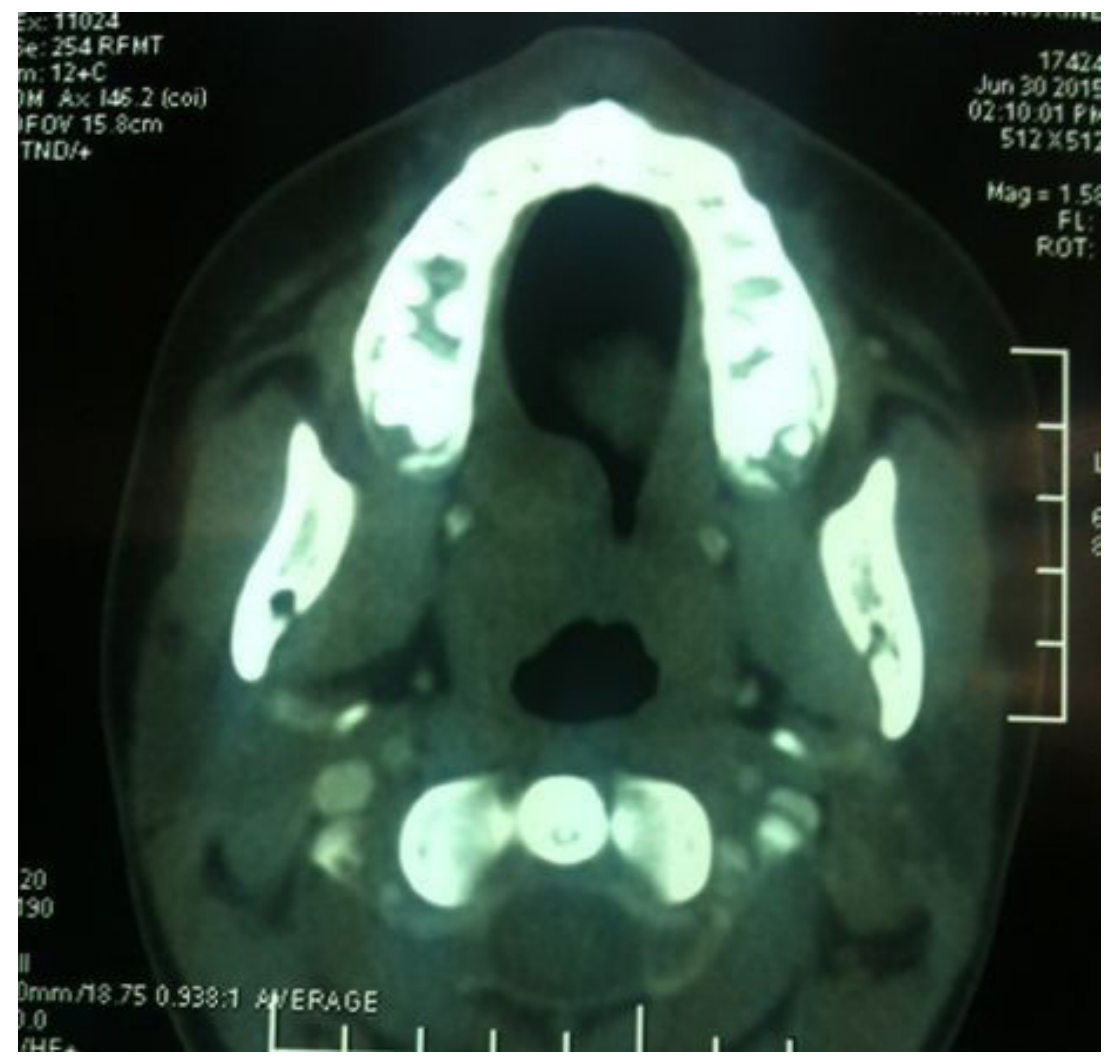

Figure 2: Computed tomography was requested which revealed a homogeneous mass, slightly less dense than the muscle

A biopsy was performed the lesion was sent for histopathological study returning a diagnosis of schwannoma, based on both the histological findings and the immunohistochemical study which was positive for protein S-100 (Figure 3).

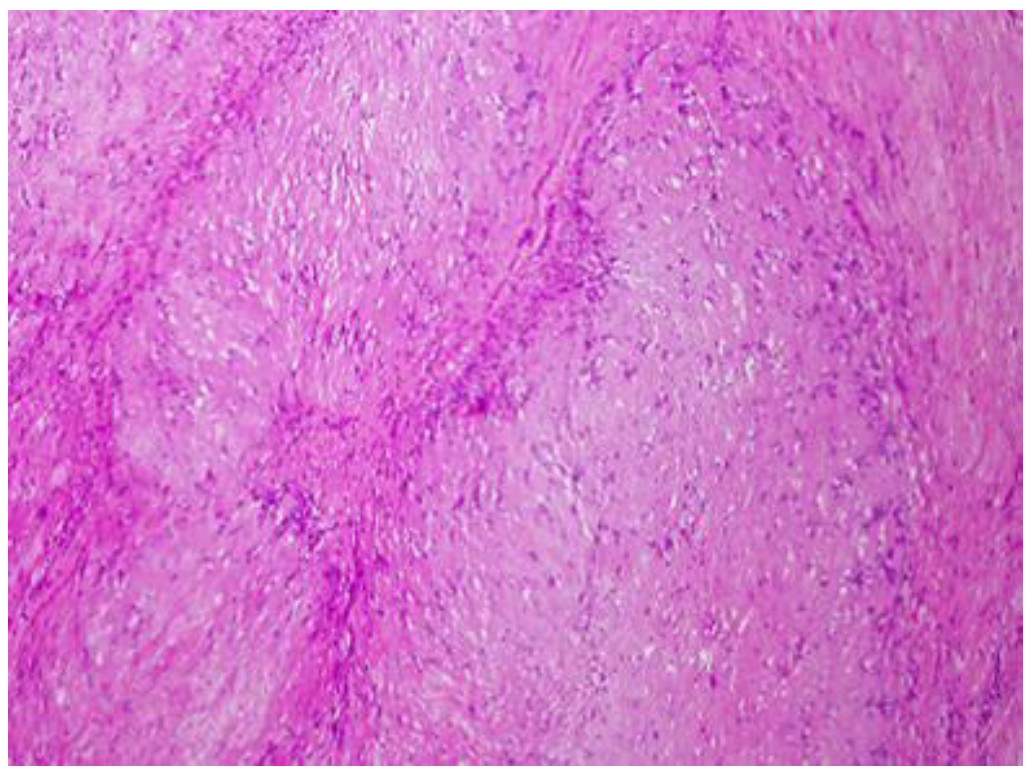

Figure 3: Slides of histopathology shows oral mucosa with salivary gland tissue and schwannoma (H\&E, 50X)

The lesion was excised completely, (Figure 4). It was not possible to identify the nerve of origin of the schwannoma, the anterior palatine nerve being a possibility. The patient evolved satisfactorily, the postoperative period was uneventful with no recurrence two years after surgery. 


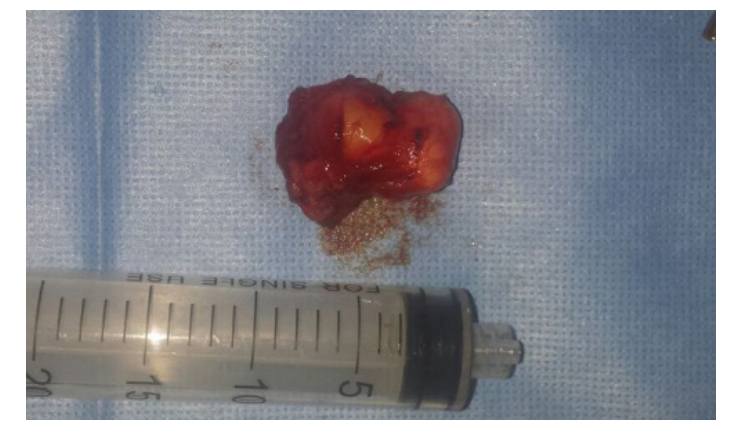

Figure 4: The postoperative appearance of the mass after resection

\section{Discussion}

Benign nerve sheath neoplasms originate from schwann cells and include schwannomas and neurofibromas. Schwannomas are encapsulated, grow eccentrically away from the nerve trunk, and can occur along any somatic or sympathetic nerve in the body (except the olfactory and optic nerves, which lack Schwann cell sheaths and which are part of the central nervous system), whereas neurofibromas involve both sheath cells and nerve fibers, exhibit diffuse proliferation, and grow within the nerve trunk.

Schwannoma is a benign tumor of unknown cause originated from the Schwann cells of the neural sheath of the peripheral nerves [1-3]. Only a 25 to $45 \%$ can be found on the head and neck region, with the parapharyngeal space being the most common site $[1,2,4,5]$. A low percentage of these lesions are present in the oral cavity and when this occurs, the tongue is the most frequently involved area [1-3]. Most of the intraoral schwannomas are placed in the soft tissues. Intraosseous localization is rare in jaw bones and represent less than $1 \%$ of benign primary tumors [1-3]. The etiology of the schwannoma is unknown. It is believed to originate from a proliferation of Schwann cells. This neural tumour can present at any age. However, it is more common between the second and third decades of life [4]. Regarding gender distribution, William and others found a male predominance whereas other studies showed equal distribution between both sexes [6,7]. In our case this was a very young patient, 15 years old.

Clinically, two forms of oral schwannoma can occur: the most frequent is where the tumour is surrounded by dense fibrous connective tissue; the other is pediculate, resembling a fibroma [8], the patient presenting with the former feature. The differential diagnosis should include neurofibromas, granular cell tumours, irritation fibromas, lymphangiomas, lipomas, pyogenic granulomas, and benign salivary gland tumors [5]. Benign salivary gland tumour and lipoma were listed as differential diagnosis in our case. The signs and symptoms of these tumors depend on the location. Most of the cases are asymptomatic and many of them have a long duration and large size because of their lack of symptoms $[9,10]$. The presence of pain, dysphagia or neurological alteration by the compression of the peri $\neg$ pheric nerves, can be observed in large sized tumors but also depends on the anatomy of the affected area $[9,10]$. Although the lesion presented in this paper had a long evolution and large size, there were no symptoms.

Imaging may add to the suspicion, but diagnosis is confirmed by pathologic examination. Because of their uncommon occurrence and nonspecific clinical presentation, the diagnosis of schwannoma is confirmed with histopathologic and immunohistochemical evaluation. Microscopic evaluation reveals an encapsulated tumor. Antoni A areas are composed of areas of hypercellular spindled cells arranged in palisades. Antoni B areas consist of edematous, myxoid-appearing stroma with few spindled cells and may also display degeneration, hemorrhage, and cyst formation [11]. Immunohistostaining commonly reveals positivity for S-100, Leu-7 antigen, vimentin, and glial fibrillary acidic protein [12] and supports the Schwann cell origin of these tumors.

The treatment of choice is complete surgical excision with particular attention to preservation of the originating nerve, if encountered. The prognosis is very good since it does not usually recur, and possibility of malignant transformation, which although rarely has been described in the literature [13].

\section{Conclusion}

Schwannoma should not be discarded when observing a tumor in the oral cavity, as in the case presented. The definitive preoperative diagnosis could only be carried out with a biopsy and anatomopathologic study. The treatment consists of surgical excision.

\section{References}

1. Artzi Z, Taicher S, Nass D (1991) Neurilemmoma of the mental nerve. J Oral Maxillofac Surg 49: 196-200.

2. Chawla O, North S, Yastes JM (2011) Schwannoma presenting in the soft palate of a nine year old boy. Dent Update 38: $327-8$.

3. Pfeifle R, Baur DA, Paulino A, Helman J (2001) Schwannoma of the tongue: report of 2 cases. J Oral Maxillofac Surg 59: 802-4.

4. López-Carriches C, Baca-Pérez-Bryan R, Montalvo-Montero S (2009) Schwannoma located in the palate: clinical case and literature review. Med Oral Patol Oral Cir Bucal 14: e465-8.

5. Nelson W, Chuprevich T, Galbraith DA (1998) Enlarging tongue mass. J Oral Maxillofac Surg 56: 224-7.

6. Martins MD, Anunciato de Jesus L, Fernandes KP, Bussadori SK, Taghloubi SA, et al. (2009) Intra-oral schwannoma: case report and literature review. Indian J Dent Res 20: 121-5. 
7. Williams HK, Cannell H, Silvester K, Williams DM (1993) Neurilemmoma of the head and neck. Br J Oral Maxillofac Surg 31: $32-5$.

8. Hribernik SJ, Gould AR, Alpert B, Jones JL (1992) Well-circumscribed mass of the lateral floor of the mouth. J Oral Maxillofac Surg 50: 741-6.

9. Subhashraj K, Balanand S, Pajaniammalle S (2009) Ancient schwannoma arising from mental nerve. A case report and review. Med Oral Patol Oral Cir Bucal 14: E12-4.

10. Zachariades N, Skoura C, Papageorgiou G, Chrissomali E (2001) Giant ancient neurilemmoma of the cervical region: report of case. J Oral Maxillofac Surg 59: 668-72.

11. Amir R, Altman KW, Zaheer S (2002) Neurilemmoma of the hard palate. J Oral Maxillofac Surg 60: 1069-71.

12. López JI, Ballestin C (1993 Intraoral schwannoma. A clinicopathologic and immunohistochemical study of nine cases. Arch Anat Cytol Pathol 41: 18-23.

13. Kun Z, Qi DY, Zhang KH (1993) A comparison between the clinical behavior of neurilemmomas in the neck and oral and maxillofacial region. J Oral Maxillofac Surg 51: 769-71. 